\title{
SUPPORT FOR TEACHING TE REO MĀORI IN PRIMARY SCHOOLS
}

\author{
Correna M. Matika* \\ Carla A. Houkamau ${ }^{\dagger}$ \\ Chris G. Sibley
}

\begin{abstract}
Te reo Māori, the Indigenous language of Aotearoa New Zealand Māori, suffered great marginalisation due to British colonisation, the effects of which are still experienced today. We interpreted national probability data from the New Zealand Attitudes and Values Study and constructed two models. Participants rated how strongly they supported teaching Māori language in New Zealand primary schools, from 1 (strongly oppose) to 7 (strongly support). Model 1 assessed how demographics related to support in $2015(N=15,821)$. Level of education (ranging from no education to $\mathrm{PhD}$ qualification) was the strongest positively correlated factor, more so than ethnicity or recent contact with Māori. Model 2 tested a latent growth model assessing the rate of change in support over six years $(2009-2015 ; N=10,437)$. Results indicate a steady increase in support over the six years and we predict this increase to continue.
\end{abstract}

\section{Keywords}

te reo Māori, language, revitalisation, longitudinal

* Ngāti Kuri, Tainui (Ngāti Wairere). Doctoral Candidate, School of Psychology, University of Auckland, Auckland, New Zealand. Email: c.matika@auckland.ac.nz

† Ngāti Porou (Te Whānau o Tūwhakairiora), Ngāti Kahungunu (Ngāti Kere). Associate Professor, Department of Management and International Business, University of Auckland, Auckland, New Zealand.

‡ Professor, School of Psychology, University of Auckland, Auckland, New Zealand. 
Ko taku reo taku ohooho; ko taku reo taku mapihi mauria.

My language is my awakening; my language is the window to my soul.

-Māori whakataukī

\section{Introduction}

The whakatauki that opens this article is well known among Māori, the Indigenous peoples of Aotearoa New Zealand. It can be interpreted as an expression of how treasured and central the Māori language is for Māori. The language is referred to as a taonga the Crown failed to protect, which it was obligated to do under the Treaty of Waitangi (Waitangi Tribunal, 1986). When the Treaty was signed in 1840 between Māori hapū and the British Crown, the population of the country was an estimated 70,000-90,000 Māori and 2,000 Pākehā (Pool, 2013). By 1901, Pākehā had already become the majority, with a population of 770,313 compared to 45,549 Māori, who had become a linguistic minority. Māori suffered (among other things) great language loss because of British assimilative policies (Bell, Harlow, \& Starks, 2005; Durie, 1998; Ka'aiMahuta, 2011), the effects of which are still experienced today. The 1867 Native Schools Act placed English as the language of instruction and learning in New Zealand schools, and in the first quarter of the 20th century at least one generation of Māori students were physically punished and traumatised for speaking their native tongue (King, 2001; Waitangi Tribunal, 1986; Walker, 1987). Language revitalisation for Māori is therefore central to broader processes of cultural reclamation. But do New Zealand residents in general now support teaching the Māori language in primary schools? And how has this support changed over time? The research reported in this article aims to investigate these attitudes and review the contexts regarding support for te reo Māori.
Previous research has recorded New Zealanders' opinions about te reo in society. Te Puni Kōkiri (2010) conducted telephone interviews with New Zealand adults across four time points, in 2000 ( $N=1,340), 2003$ $(N=1,500), 2006(N=1,500)$ and 2009 $(N=1,531)$. Interviews assessed Māori and non-Māori support for things like government involvement in Māori language revitalisation and attitudes towards te reo Māori. Results from the interviews indicated an increase in support for the language and government involvement across the nine years among both Māori and non-Māori. A limitation of Te Puni Kōkiri's study is that different people were interviewed over the four time points at which the surveys were conducted. To reliably assess how people's attitudes change over time, collecting data from the same people over multiple time points is better (Frees, 2004). New Zealand has also changed greatly in the past decade so it would be appropriate to observe how attitudes may have changed in that time.

The research reported here aims to improve on previous studies by utilising the New Zealand Attitudes and Values Study (NZAVS). The NZAVS is a large national probability panel study that has been annually posted to the same participants since 2009. Here we interpret existing NZAVS data to understand two key questions about support for teaching te reo. First, we analyse participants' support for teaching te reo in relation to a range of demographics such as their education level, region of residence or recent interaction with Māori. Second, because the NZAVS samples the same people annually and has included the same item assessing support for teaching te reo in schools each year, we can examine people's rate of change in support for Māori language in schools from 2009 to 2015. 


\section{Demographic support for te reo}

So who is supportive of te reo Māori/English bilingualism? Nicholson and Garland (1991) found that "Māori respondents, younger people and women favoured [te reo Māori/English] bilingualism more than their European, older and male counterparts" (p. 393). These results are consistent with studies such as Te Puni Kōkiri's (2010) research which found that although both Māori and non-Māori are mostly supportive of te reo Māori revitalisation, Māori report higher levels of positive attitudes towards the language and its revitalisation than nonMāori. The Social and Population Statistics Group of Statistics New Zealand (SPSGSNZ, 2002) found that women tend to have higher proficiency in te reo than men. Although this does not necessarily mean that women are more supportive of the language than men, it may indicate that women engage with te reo more than men. SPSGSNZ suggest this may happen because women tend to volunteer at kōhanga reo or are more likely to be involved with their children's education. In the New Zealand Census, Māori women are more likely to report an iwi than Māori men, which Kukutai and Rarere (2015) contend could be due to Māori women, especially mothers, being the cultural transmitters of their whānau.

There may also be regional differences in attitudes towards te reo. A study by Te Puni Kōkiri (2008) found that northern regions like Te Tai Tokerau have high te reo speaker rates $(28 \%)$, which they acknowledge may exist because the population is more densely Māori in northern regions. Census data reveal a similar pattern, where Māori are much more likely to know and report their iwi in regions with higher proportions of Māori people (see Kukutai \& Rarere, 2015). This may mean that regions such as Te Tai Tokerau are more supportive of teaching te reo than areas with proportionately fewer Māori (and fewer te reo speakers), like Southland. To be more certain about possible regional differences, it would be useful to observe support for te reo specifically by region.

International theory offers potential ways to explore support for te reo. The contact hypothesis (Allport, 1954) theorises that contact between members of different groups is associated with positive relations and reduced prejudice between groups. Pettigrew and Tropp (2008) state that this occurs because interacting with out-group members increases in-group members' knowledge of, empathy for and warmth towards the out-group and its members. Fortuitously, the NZAVS asked participants to state their hours spent with Māori (friends/family, work/other contexts), so we are able to analyse existing data looking to determine whether being in contact recently with Māori is related to support for teaching te reo. Research by Sengupta, Barlow and Sibley (2012) showed that for both Māori and New Zealand Europeans contact with Māori friends was positively linked with the belief that Māori culture is relevant in representations of New Zealand identity. This may indicate that those who recently interacted with Māori (relative to those who did not) have warmer attitudes towards Māori signifiers (such as the language) and therefore are more supportive of te reo.

Recently, there seems to have been an increase in support for the use of te reo Māori across New Zealand society. There has been increased visibility and usage of te reo on national television (Radio New Zealand, 2015), with correct pronunciation being used in sports commentary (Harrison, 2016); media stories devoted to keeping te reo alive (e.g., Collins, 2016); and an increase in te reo lessons on a more personal level (Tuckey, 2016). Thus, there is some indirect evidence that New Zealanders are warming towards the use of te reo Māori. At the same time, we researchers recognise that although these specific media examples depict supportive attitudes towards te reo Māori, previous research has consistently shown that New Zealand media portray Māori negatively and that news about Māori is relatively rare 
(see Nairn et al., 2012). Nicholson and Garland (1991) acknowledged that media is a powerful influence and found that non-Māori were much more supportive of te reo in written media like newspapers and magazines than te reo television programming. Nicholson and Garland suggest this is because non-Māori can have more choice in the written media they engage with. This highlights an important uncertainty: How can research separate passive tolerance from active support? In the NZAVS, participants were asked to indicate how strongly they support teaching te reo, so a neutral answer may indicate passive tolerance, less support might suggest opposition and high support might imply active support for teaching te reo.

\section{Overview and guiding hypotheses}

History has shown that Māori are resilient and that their culture and language have prevailed through hardship (Reedy, 2000). Information on New Zealand opinions about te reo is due for an update. Historically, methods for measuring support have tended to compare Māori with non-Māori views. We address this by analysing self-reported questionnaire data from the NZAVS to get a large-scale overview of New Zealand residents' ratings of support for teaching te reo Māori in schools. Two models were employed to measure nationwide support in 2015. Model 1 utilised demographic factors and Model 2 investigated the changing rate of support from 2009 to 2015.

\section{Model 1: Demographic factors}

The purpose of Model 1 was to provide an important update on current New Zealander attitudes towards teaching te reo Māori in New Zealand primary schools taking into account a range of demographic factors. In Model 1 we expected that women would be more supportive of te reo in schools than men as they are reportedly more likely to be involved with
Māori culture and their children's education (Kukutai \& Rarere, 2015; SPSGSNZ, 2002). One might also expect that, as found in Te Puni Kōkiri studies, Māori would be more supportive of teaching te reo than their non-Māori counterparts. Hypothetically, regions that have proportionately higher Māori populations would show more support for teaching te reo, as noted above. In line with contact theory, participants who interact with Māori would also likely be more supportive than those who have no contact with Māori.

\section{Model 2: Tracking change}

Model 2 aims to give an overview of the changing rate of New Zealand resident support towards teaching te reo in primary schools over the years 2009-2015. A projected level of support for 2018 is also offered, with the assumption that no dramatic changes occurred during the interim. Consistent with findings from Te Puni Kōkiri (2010), and in line with some recent media portrayals of te reo usage, we expect an upwards trend of support among New Zealanders for teaching te reo to be prevalent in the existing NZAVS data. More specifically, a positive growth parameter is expected, indicating that support for te reo in schools has been gradually and significantly increasing over the 2009-2015 period in the New Zealand population.

\section{Model 1}

\section{Method}

The following analyses are based on data from Wave 6 of the NZAVS, collected in 2015. The NZAVS uses the electoral roll as the sample frame. See Sibley (2019) for full details about the sampling procedure for the NZAVS.

Participants were 15,821 people who completed the Wave 6 NZAVS questionnaire during the October 2014-October 2015 period. The 
largest known sample bias in the NZAVS is that women are more likely to respond than men (10,003 women, 5,798 men, 20 gender diverse). With regard to ethnicity, 14,162 (89.5\%) identified as European, 1977 (12.5\%) identified as Māori, 526 (3.3\%) identified as being of Pacific ancestry, 684 (4.3\%) identified with an Asian ethnic group and 388 (2.5\%) identified as an ethnicity other than European, Māori, Pacific or Asian. Ethnic group counts were not mutually exclusive, as people could identify with more than one ethnic group.

Participants had a median household income of NZ\$89,776 ( $M=108,276 ; S D=119,918$; 1,143 missing) and a mean age of 49.34 years ( $S D=14.04$, range 18-95; 9 missing). The mean decile-ranked deprivation of participants' immediate neighbourhood (meshblock) was 4.71 ( $S D=2.76$; range 1-10, 252 missing; see Atkinson, Salmond, \& Crampton, 2014). Education was scored using a $0-10$ ordinal ranking, with 0 being no education and 10 being a $\mathrm{PhD}$ or equivalent qualification $(M=5.05$, $S D=2.85,1,114$ missing; see New Zealand Qualifications Authority, 2016). Participants' socio-economic status was indexed using the New Zealand Socio-economic Index, based on occupational status $(M=54.06, S D=16.82$, range 10-90, 3,716 missing; see Milne, Byun, $\&$ Lee, 2013).

With regard to other demographic factors, 10,455 lived in urban regions and 5,158 in rural regions (208 missing), 12,039 were employed and 3,595 were not employed (187 missing). Some 11,346 participants were in a serious romantic relationship and 3,836 were not (639 missing); 11,613 were parents and 3,950 were not (258 missing). A total of 6,013 were religious and 9,117 were not (691 missing).

In terms of regions, $30.6 \%$ of participants were from Auckland ( $n=4,840), 14.1 \%$ from Wellington $(n=2,224), 13.6 \%$ from Canterbury $(n=2,153), 8.2 \%$ from Waikato ( $n=1,292), 5.8 \%$ from Bay of Plenty $(n=913)$, $5.4 \%$ from Otago $(n=853), 4.9 \%$ from the Manawatu-Wanganui region $(n=783), 3.5 \%$ from Hawke's Bay $(n=549), 3.2 \%$ from Northland $(n=505), 2.3 \%$ from Taranaki ( $n=362), 1.8 \%$ from Southland ( $n=287)$, $1.4 \%$ from Nelson $(n=226), 1.3 \%$ from the Tasman region $(n=208), 1.1 \%$ from Marlborough $(n=178), 0.8 \%$ from Gisborne $(n=121)$ and $0.7 \%$ were from the West Coast ( $n=117$ ), with 209 missing.

As part of the NZAVS survey, participants were asked to rate how strongly they opposed or supported "Teaching Māori language in New Zealand primary schools" on a scale from 1 (strongly oppose) to 7 (strongly support).

To measure whether participants had interacted with a Māori person or persons in the week before they completed the survey, they were asked "Roughly how many hours have you spent with both FRIENDS/FAMILY and OTHERS (e.g., workmates, strangers) from each ethnic group in the last week?" We only used data regarding hours spent with Māori friends/family and Māori others for this article. Reported hours were extremely skewed, and there were many 0 scores (indicating no interaction). Accordingly, a categorical indicator representing yes/no was created as to whether people had interacted with Māori (whether friend, family or other) in the past week.

A multiple regression model was constructed using existing NZAVS data to assess the degree to which different demographic factors were associated with support for teaching Māori language in schools. The maximum likelihood method was used, with robust estimation of standard errors. Missing data for exogenous variables were estimated using Rubin's (1987) procedure for multiple imputation with parameter estimates averaged over 1,000 datasets (thinned using every 200th iteration). Table 1 presents the results of the regression model. Model 1 tests the extent to which each demographic factor was associated with support for te reo in schools when controlling for all other demographic factors in the model. 


\section{Results}

Mean levels of support for teaching Māori language in schools are presented in the following graphs by ethnicity and gender and then across different regions of New Zealand. Figure 1 shows the mean levels of support by ethnicity and gender. Analysis of variance (ANOVA) used to test differences in support for teaching te reo in schools by ethnicity and gender was significant, and the overall effect size was small, indicating that, overall, the differences accounted for $8.2 \%$ of the variance $\left(F_{(3,15356)}=13.78, p<.001\right.$, partial $\left.\eta^{2}=.082\right)$. Māori women $(M=5.95, S D=1.23)$ were significantly more supportive of te reo Māori being taught in schools than New Zealand European women $(M=4.95, S D=1.53, p<.001)$, Pacific women $(M=5.33, S D=2.39, p<.001)$ and
Asian women $(M=4.75, S D=2.86, p<.001)$. Support for teaching te reo did not differ between genders for Pacific peoples (Pacific men $M=5.24, S D=2.90, p=.426)$. Women were more supportive of teaching te reo in schools than men across the other three ethnicities (New Zealand European men $[M=4.18, S D=1.88$, $p<.001]$, Māori men $[M=5.50, S D=1.88$, $p<.001]$ and Asian men $[M=4.20, S D=3.01$, $p<.001])$. Māori men were also significantly more supportive of teaching te reo relative to non-Māori men. New Zealand European men did not significantly differ in terms of their support for teaching te reo compared to Asian men $(p=.719)$.

Figure 2 shows the mean levels of support for teaching te reo in schools across regions. Gisborne showed the highest overall mean level of support $(M=5.05)$, whereas Southland

TABLE 1 Regression model predicting support for teaching te reo Māori in New Zealand primary schools

\begin{tabular}{lrrrrc}
\hline & $b$ & $s e$ & \multicolumn{1}{c}{$\beta$} & \multicolumn{1}{c}{$t$} & \multicolumn{1}{c}{$p$} \\
\hline Intercept & \multicolumn{1}{c}{$\boldsymbol{c}(128$} & .114 & 2.808 & 45.034 & .000 \\
Gender (0 women, 1 men) & -.590 & .029 & -.156 & -20.180 & .000 \\
Age & -.019 & .001 & -.146 & -16.438 & .000 \\
Age $^{2}$ & .000 & .000 & -.019 & -2.238 & .025 \\
Household income (10,000 units) & -.001 & .002 & -.006 & -.773 & .440 \\
Deprivation Index (1-10) & .027 & .005 & .041 & 4.978 & .000 \\
NZSEI (10-90) & .006 & .001 & .053 & 5.639 & .000 \\
Education (0-10) & .130 & .006 & .200 & 20.804 & .000 \\
European (0 no, 1 yes) & -.624 & .060 & -.104 & -10.343 & .000 \\
Pacific (0 no, 1 yes) & .085 & .086 & .008 & .985 & .325 \\
Asian (0 no, 1 yes) & -.980 & .086 & -.109 & -11.458 & .000 \\
Religious (0 no, 1 yes) & .050 & .029 & .013 & 1.733 & .083 \\
Parent (0 no, 1 yes) & -.019 & .037 & -.005 & -.514 & .607 \\
Partner (0 no, 1 yes) & -.018 & .035 & -.004 & -.526 & .599 \\
Employed (0 no, 1 yes) & -.052 & .038 & -.012 & -1.382 & .167 \\
Urban (0 no, 1 yes) & .093 & .031 & .024 & 3.034 & .002 \\
Interacted with Māori (0 no, 1 yes) & .555 & .031 & .147 & 18.056 & .000 \\
\hline
\end{tabular}

Note. NZSEI = New Zealand Socio-economic Index. Model estimated using multiple imputation with 1,000 datasets for missing values for the predictor variables. Fit statistics for teaching te reo Māori in New Zealand primary schools: $R^{2}=.159$, $s e=.005, t=29.462, p<.001$. 

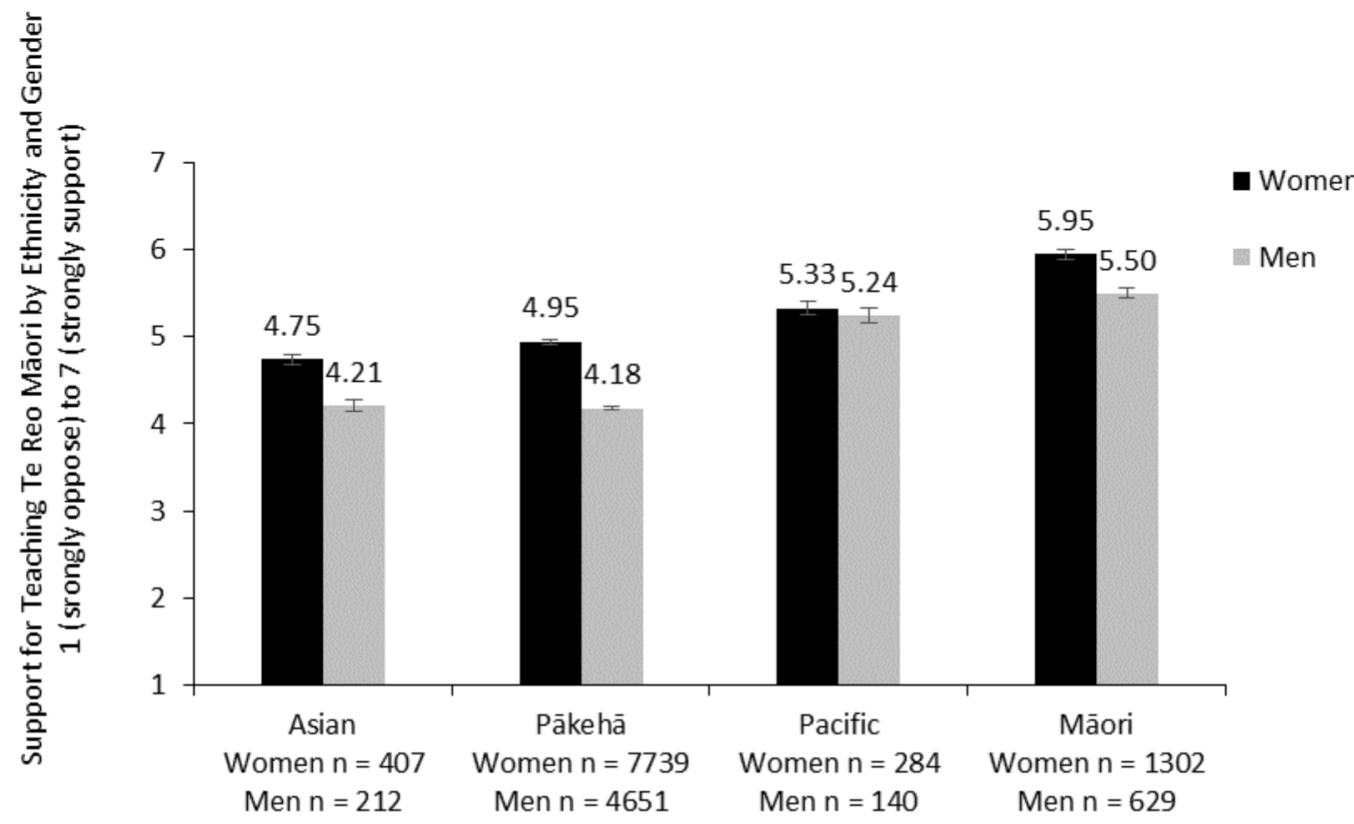

FIGURE 1 Support for teaching te reo Māori by ethnicity and gender Note. Standard sample weighting applied.

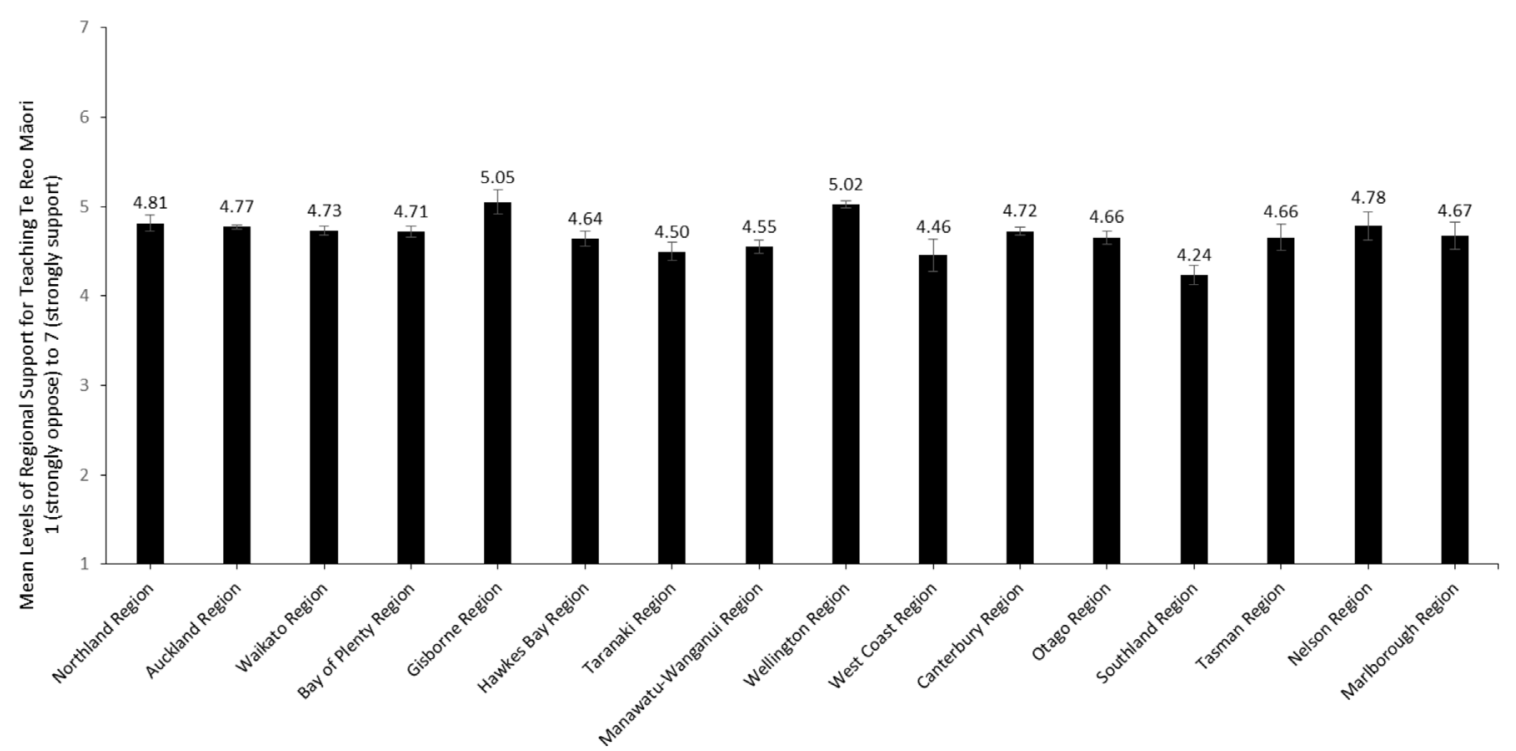

FIGURE 2 Support for teaching te reo Māori by region Note. Standard sample weighting applied.

showed the lowest overall mean level of support $(M=4.24)$. An ANOVA assessing differences in support for teaching te reo in primary schools across council regions was significant, although the overall effect size was very small, indicating that, overall, the differences were trivial and accounted for only $0.6 \%$ of the variance $\left(F_{(16,15355)}=6.12, p<.001\right.$, partial $\left.\eta^{2}=.006\right)$. 


\section{Regression model}

Significant effects in the regression model indicate that a demographic factor was associated with support when controlling for all other variables in the model. As reported in Table 1, women and younger people were more supportive of te reo in schools. Household income was not associated with support. People who lived in more deprived regions were more supportive, as were people with higher socio-economic status. People with a higher level of education were more supportive. Note that education was the strongest predictor of support $(\beta=.200)$. People who lived in an urban environment were more supportive relative to those who lived in rural areas.

Religious people and parents did not differ from their respective non-religious and nonparent counterparts in terms of support for teaching te reo. Whether or not people had a romantic partner or were employed was unrelated to their level of support. People who had interacted with Māori in the week prior to filling out the questionnaire were more supportive of teaching Māori language in schools. Note that the standardised beta $(\beta=.147)$ indicates that this effect was also relatively strong compared to most other factors in the model.

\section{Model 2}

\section{Method}

The following analyses are based on existing data from 10,437 participants who completed at least three of the first six annual waves of the NZAVS, from October 2009 to October 2015. Booster samples were conducted during Waves 3, 4 and 5 to help maintain the representation of the sample size and adjust for sample attrition. A technical analysis of sample attrition is published in Satherley et al. (2015).

As part of the first six waves of the annually posted NZAVS survey, participants reported how strongly they opposed or supported “Teaching Māori language in New Zealand primary schools" on a scale from 1 (strongly oppose) to 7 (strongly support).

A latent growth model was estimated to assess the rate of change in levels of support for teaching the Māori language in New Zealand primary schools over the October 2009-October 2015 period. The analysis only included participants who had responded to three or more waves. The samples sizes on which the models are based are as follows: Wave $1(n=4,633)$, Wave $2(n=4,012)$, Wave $3(n=6,154$, Wave $4(n=9,518)$, Wave 5 $(n=9,433)$, Wave $6(n=9,091)$.

Missing data among those completing at least three waves were estimated using the full information maximum likelihood method, assuming that data were missing at random. This method of missing data estimation weighted each individual-level trajectory based on its reliability, which in turn is a function that takes the number of observations into account. Those who responded to all six time points contributed the most information to the estimation of the mean-level trajectory, while those who responded to only three contributed the least.

To reflect the variation in response time to each wave between individuals, response time at each wave was then converted into yearly units and modelled as individually time-varying effects, with time $=0$ being 30 June 2009. This accounted for the fact that different individuals completed the surveys at different times throughout the year, and with different durations between each assessment, rather than fixing all responses in 2009 to 1, all responses in 2010 to 2, and so forth. The model provides a latent intercept representing estimated mean support at 30 June 2009. Residual variances, or disturbances, in the manifest ratings of the support for te reo item were constrained to equality across waves. We therefore assumed that the amount of variation that is unexplained by the intercept and rate of change in the outcome 


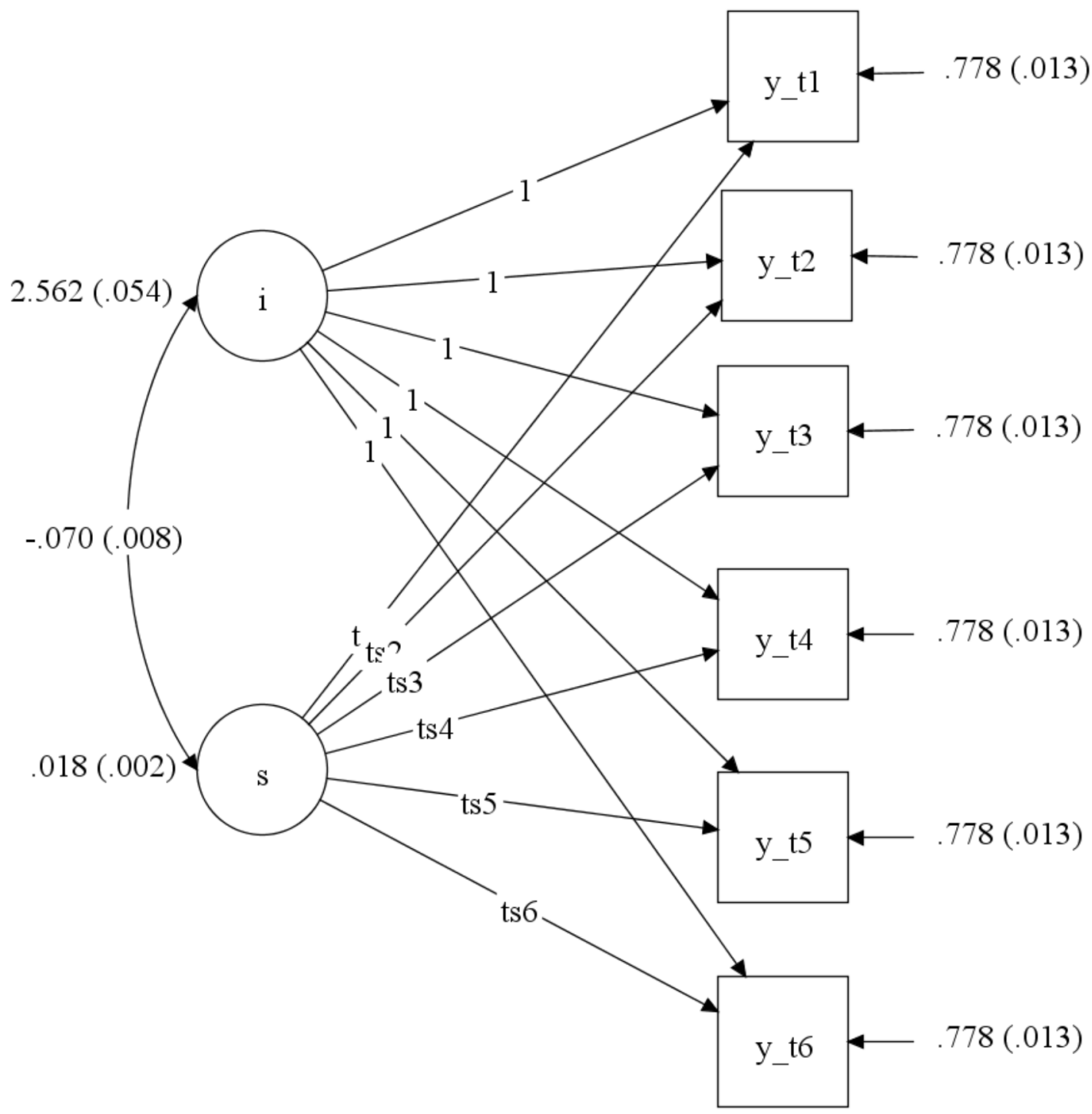

FIGURE 3 Graphical representation of the latent growth models

Note. Time score (ts) values represent the linear effect of time-varying values; $i=$ intercept, $s=$ linear growth component.

measure is the same across waves (see Grimm \& Widaman, 2010).

Figure 3 presents a structural equation model outlining the modelling approach. The model estimated the fixed and random effect for the intercept, linear growth component and quadratic growth component spanning Waves 1-6 of data collection. The intercept represents the mean score on the outcome (level of support) as of July 2009. The slope or linear component loads onto each measurement point as a function of the time score, or time at which the measurement was made (in Figure 3, TS1 = day of survey completion during Time 1, TS2 = day of survey completion during Time 2, etc.).

Support for teaching Māori language in New Zealand primary schools was then estimated at three-month intervals in January, A pril, July and October. That is, estimates were obtained every three months from October 2009 to October 2015. These months also roughly coincide with peak times of data collection for the NZAVS.

The parameters for the fixed effects were integrated into the model to generate the model-implied rate of change in support over the period October 2009-October 2015. The 
regression equation used to estimate this modelimplied rate is presented in Equation 1.0, where $y_{t}$ is the predicted level of support at time $t, c$ is the intercept, or model-predicted mean level of support when $t=0$ (i.e., 30 June 2009), and $s$ is the fixed effect for the linear growth component of the model. Values of $t$ are distributed in this model so that 1.0 unit represents a change of one year.

$$
y_{t}=c+s t
$$

Parameters reported in Table 2 were used to derive model-implied levels of support for teaching Māori language in New Zealand primary schools for values of $t$ ranging from .25 (October 2009) to 6.25 (October 2015).

\section{Results}

The growth parameters modelling the rate of change in support for teaching te reo in schools were significant and indicated a gradual and steady increase over time (see Table 2). The random effects for the intercept were also significant, indicating that there were significant individual differences in New Zealand residents' overall levels of support for teaching te reo Māori. Also, the significant random effects for the slope indicate that people differed in the extent to which their support altered over time. The analysis provides an estimate of the current level of support and the rate of change in support for teaching te reo Māori in New Zealand primary schools.

The model was extended to forecast the linear rate of change in support for teaching Māori language up until January 2018. Care must be taken when interpreting this forecast, but if conditions continue as they are, then this estimate of where levels of support could be in early 2018 reflects a continued increase.

\section{Discussion}

If the increased use of te reo on the radio and television and in schools is anything to go by, the endorsement of te reo Māori by New Zealanders is also increasing. In this article, data were analysed from participant surveys in the NZAVS to answer two questions: (a) Do New Zealanders in general support teaching the Māori language in primary schools? and

TABLE 2 Fixed and random effects for latent growth model predicting change in support (on a scale from 1 to 7) for "Teaching Māori language in New Zealand primary schools" for New Zealand residents over the October 2009-October 2015 period

\begin{tabular}{lrrrr}
\hline & $b$ & \multicolumn{1}{c}{$\boldsymbol{s} \boldsymbol{c}$} & \multicolumn{1}{c}{$\boldsymbol{t}$} \\
\hline Fixed effects (means) & & & & \\
Intercept & 5.264 & .020 & 267.70 & .001 \\
Linear growth parameter & .014 & .003 & 4.26 & .001 \\
Random effects (variances) & & & & \\
Intercept & 2.562 & .054 & 47.07 & .001 \\
Linear growth parameter & .018 & .002 & 9.42 & .001 \\
Covariances & & & & \\
Intercept-linear parameter & -.070 & .008 & -8.84 & .001 \\
\hline
\end{tabular}

Note. Models estimated using maximum likelihood with robust estimation of standard errors. Standard errors reported in parentheses. Disturbances of the manifest indicators were constrained to equality over time. Participants who completed fewer than 3 of the 6 waves were excluded from the model. Missing data among participants who completed 3 or more waves were estimated using full information maximum likelihood and assuming data were missing at random. Fit indices: loglikelihood $=-69584, \mathrm{AIC}=139181, \mathrm{BIC}=139225$. 


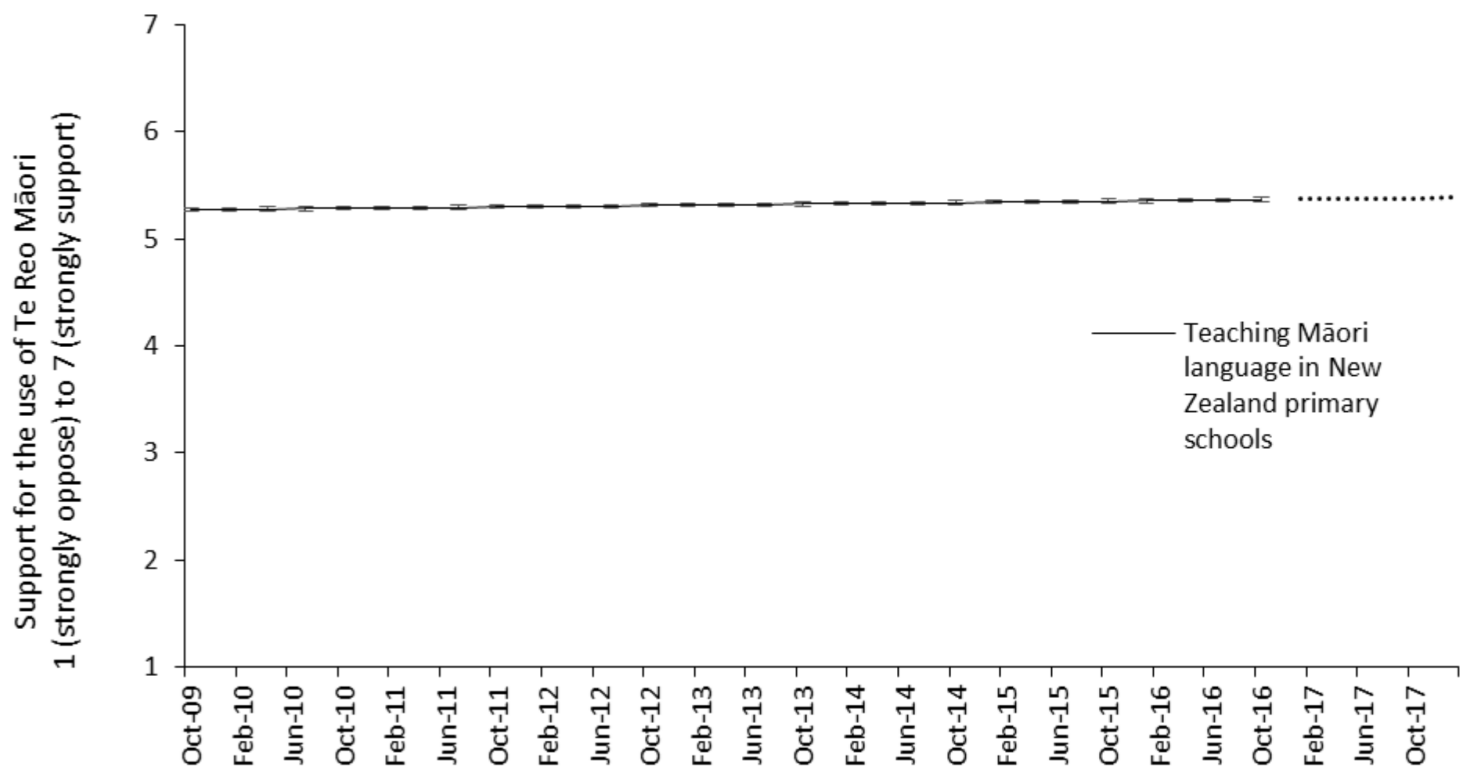

FIGURE 4 Rate of increase in support for teaching te reo Māori in schools over the 2009-2015 period, with dashed line showing forecasted continual increase from 2016 to 2018

(b) How has this support changed over time? Two notable strengths of the NZAVS that are directly related to both questions is that the study has a sizeable representative sample of participants and longitudinally surveys the same participants annually. Findings suggest that New Zealanders of diverse backgrounds and experiences have varied attitudes towards teaching te reo in school. Previous research has been restricted in the conclusions that can be drawn, largely because sample sizes were limited or studies were cross-sectional, utilising new participants each survey.

A gradual and steady increase in support for teaching the Māori language in primary schools was observed and baseline predictions of where levels of support were in 2018 (based on the observed rate of change in participants attitudes over October 2009 to October 2015) was provided. This documentation can inform policy by tracking changes in support after different policies are implemented. For example, if policies changed and a dramatic increase in support for te reo was observed (utilising techniques from this study), this could imply that those changes in policy were effective (or vice versa). Clearly, the models presented here could prove to be important tools for te reo Māori revitalisation efforts. Future qualitative research could interview New Zealanders to further investigate why attitudes may have changed. For the time being, this article serves to provide a clearer picture of New Zealander support for teaching te reo in primary schools and shows an encouraging environment for the future normalisation of the language.

Past research has often found that Māori are more supportive of teaching te reo than non-Māori. More specifically, analyses from the current study showed that Māori women were more supportive of teaching te reo in contrast to New Zealand European, Pacific and Asian women. Māori men were also more supportive than New Zealand European, Pacific and Asian men. This study was able to identify that women were more supportive of teaching te reo in schools than men across Māori, New Zealand European and Asian ethnicities. However, Pacific men and women had similar levels of support-that is, Pacific peoples' 
support for teaching te reo did not significantly differ between genders. New Zealand European men also did not significantly differ in terms of their support for teaching te reo from Asian men. It seems no other research has documented this. These differences may have been detected because the data come from a large sample, whereas other research may have grouped New Zealand European, Pacific and Asian peoples into a single non-Māori category. Revitalisation efforts therefore may benefit from approaching European, Pacific and Asian males to understand how to increase their support for teaching te reo in schools and the ways in which this may affect their communities. This highlights an important area for improving support since Europeans (74\%), Pacific peoples $(7 \%)$ and Asians (12\%) make up the other major ethnic groups of New Zealand (Statistics New Zealand, 2013a). Future researchers may want to consider gender identity and how this could relate to support for te reo Māori.

Kōhanga reo and kura kaupapa Māori are important sites for the use and revitalisation of the Māori language (King, 2001), but could other sites of education also foster positive views towards te reo Māori? The current study suggests that people who pursue higher education are also more likely to support teaching te reo in primary schools, and this was the strongest predictor when looking across all other factors. However, care needs to be taken when interpreting this result, as it must be acknowledged that higher education is often associated with other social privileges. Those who are privileged to be able to complete higher education are often more aware of the experiences and opportunities of others. This could be a key area for te reo revitalisation efforts to look into, encouraging people with higher levels of education (who are more likely to be supportive of te reo and accustomed to navigating institutional systems) to become agents of progressive cultural shift and actively support te reo.

Keeping in mind the harm done to generations of Māori by British colonisation, there are still important educational disparities between Māori and the majority. An Organisation for Economic Co-operation and Development report that looked at tertiary education stated that Māori are "concentrated in the lower levels of the tertiary education pathways" (Santiago, Tremblay, Basri, \& Arnal, 2008, p. 92). This gains a new perspective in terms of the results of this study, where Māori were found to be more supportive of teaching te reo at the same time as people with lower levels of education were found to be less supportive. Perhaps Māori are more supportive of teaching te reo in schools irrespective of their level of education. Participants who have lower levels of education may not necessarily be opposed to te reo in schools; they may not have access to the ideas that higher-educated people are exposed to. An additional benefit of teaching te reo in all New Zealand primary schools is that it will expose people from all walks of life to the benefits of learning the Indigenous language of New Zealand.

Interesting findings from this study regarding participants' income, deprivation, employment and socio-economic status pose more questions for revitalisation efforts to investigate. Both people living in neighbourhoods of high deprivation and individuals with high socio-economic status were more supportive of teaching the Māori language in schools in comparison to their low deprivation neighbourhood and low socio-economic counterparts. Yet at the same time participants' household incomes and employment statuses were not related to support for te reo. This suggests that social factors rather than actual income or employment influence an individual's attitude towards te reo.

Why then might those who appear to have such distinct and contrasting life experiences nevertheless all support teaching te reo in schools? As mentioned, those with higher education showed more support, and as socio-economic positioning was measured by occupational status, it would be not be surprising for higher 
education to lead to occupations with higher socio-economic status, which was associated with support for te reo in schools. At the same time, Māori are "over-represented at the more deprived and under-represented at the less deprived end of the deprivation spectrum" (Tobias, Bhattacharya, \& White, 2008, p. 431). Results showed that Māori are supportive of te reo, and if Māori are over-represented in deprived neighbourhoods, so it is again unsurprising that higher levels of deprivation are also related to support. Interestingly, it may be of benefit for revitalisation efforts to acknowledge these communities' differing and potential strengths. High socio-economic status individuals are likely to be well resourced and well educated, while individuals living in high deprivation areas will have valuable life experiences and perhaps important cultural knowledge.

A wide range of other demographics not previously looked at in other studies were analysed from existing NZAVS data, indicating what aspects of New Zealand residents' lives may or may not be related to their attitude towards teaching te reo. Living in an urban area was associated with more support for teaching te reo Māori in primary schools. This may be because living rurally limits access to physical and cultural resources. Again, as with the education finding, it is not clear whether those who live rurally are actively opposed to teaching te reo or passively unsupportive since they may not have encountered the relevant concepts. The Southland region had the lowest mean level of support, whereas Gisborne had the highest. This may reflect the dense Māori population of Gisborne (where 49\% identify as Māori); in contrast only $13 \%$ of the Southland region identify as Māori (Statistics New Zealand, 2013b). It therefore seems important to implement teaching te reo across all primary schools so that those who live rurally or in less densely Māori-populated regions are exposed to the benefits of learning and speaking the language.

Participants who reported having some form of contact with Māori in the week before they filled out the questionnaire were significantly more supportive of teaching te reo than those who reported no contact. This aligns with contact theory and provides the te reo revitalisation field with empirical evidence that contact and support for teaching te reo are positively correlated. Importantly, this suggests revitalisation efforts should take a broader approach to encouraging the use of te reo by developing positive intergroup relations to foster more active support from otherwise passive or unsupportive people who (based on current findings) are not likely to have contact with Māori, whether intentional or not. One might speculate that future research looking into these factors would show that positive correlations exists between contact, warmth towards Māori and support for te reo or Māori culture in general.

\section{Concluding comments}

Results from Model 1 back the idea that integrated efforts may encourage effective support for te reo, and results from Model 2 indicate that New Zealanders are becoming more supportive of teaching Māori language in schools over time. Commitment to engage in revitalisation activities is needed from both Māori and non-Māori. As Hornberger (1998) powerfully explains, "Revitalization efforts are not about bringing the language back, but rather about bringing it forward” (p. 453). If non-Māori were also involved in the revitalisation process, te reo Māori would be more likely to thrive, and maybe even achieve the same status as the currently dominant English language, at which point speaking te reo could become the norm in New Zealand society.

The current study based on NZAVS data offers practical suggestions for how support for teaching te reo may be improved. Fostering positive intergroup contact between Māori, New Zealand European, Pacific and Asian communities may develop active support from (passively or actively) unsupportive people. This same 
motif is relevant for the implementation of te reo in New Zealand primary schools, because this would increase the chance of exposure to the language for individuals who may not have access to it (e.g., those who live rurally or in areas less densely populated with Māori). Again, bringing people who may not usually interact together, such as those who have high socio-economic status and those who live in high deprivation areas may be a source of shared knowledge and resources and create a common stance in support of teaching Māori language in schools. Finally, level of education qualification was the strongest predictor and appropriately can be seen as a foundation for the empowerment of support for te reo in schools. We have provided here a comprehensive picture of how New Zealanders' support for teaching the Māori language in primary schools has changed over the period 2009-2015 and estimated what the level of support was in 2018. It is the authors' hope that the insights offered here will inspire future revitalisation efforts.

\section{Acknowledgements}

CMM thanks her iwi Ngāti Kuri, Tainui (Ngāti Wairere) and whānau for their unwavering strength. This article is based on CMM's honours thesis, supervised by $\mathrm{CS}$ and $\mathrm{CH}$. The authors thank Lucy Te Moana, Mikaia Leach and Te Taura Whiri i te Reo Māori for their support and helpful comments in preparing this research. Data collection for the NZAVS was supported by a grant from the Templeton Religion Trust (TRT0196). Mplus syntax for the models reported is available on the NZAVS website (http://www.psych.auckland.ac.nz/uoa/ NZAVS).

\section{Glossary}

\begin{tabular}{|c|c|}
\hline hapū & $\begin{array}{l}\text { kinship group, clan, } \\
\text { subtribe }\end{array}$ \\
\hline iwi & tribe \\
\hline kōhanga reo & $\begin{array}{l}\text { lit., "language nest”, } \\
\text { full immersion Māori } \\
\text { preschool }\end{array}$ \\
\hline $\begin{array}{l}\text { kura kaupapa } \\
\text { Māori }\end{array}$ & $\begin{array}{l}\text { total immersion Māori } \\
\text { school }\end{array}$ \\
\hline Māori & $\begin{array}{l}\text { the Indigenous peoples of } \\
\text { New Zealand }\end{array}$ \\
\hline $\begin{array}{l}\text { Pākehā } \\
\text { taonga }\end{array}$ & $\begin{array}{l}\text { New Zealand European } \\
\text { treasured possession }\end{array}$ \\
\hline Te Puni Kōkiri & $\begin{array}{l}\text { Ministry of Māori } \\
\text { Development }\end{array}$ \\
\hline te reo Māori & the Māori language \\
\hline $\begin{array}{l}\text { Te Tai Tokerau } \\
\text { whakataukī }\end{array}$ & $\begin{array}{l}\text { Northland region } \\
\text { proverb }\end{array}$ \\
\hline
\end{tabular}

kinship group, clan, tribe "language nest", full immersion Māori (noo Indigenous peoples of New Zealand European treasured possession Ministry of Māori the Māori language proverb 


\section{References}

Allport, G. W. (1954). The nature of prejudice. Reading, MA: Addison-Wesley.

Atkinson, J., Salmond, C., \& Crampton, P. (2014). NZDep2013 Index of Deprivation. Retrieved from https://www.otago.ac.nz/wellington/ otago069936.pdf

Bell, A., Harlow, R., \& Starks, D. (Eds.). (2005). Languages of New Zealand. Wellington, New Zealand: Victoria University Press.

Collins, M. (2016). Te reo-only day keeps language alive. New Zealand Herald. Retrieved from http://www.nzherald.co.nz

Durie, A. (1998). Emancipatory Māori education: Speaking from the heart. Language, Culture and Curriculum, 11(3), 297-308. http://doi. org/bzndzm

Frees, E. W. (2004). Longitudinal and panel data: Analysis and applications in the social sciences. Cambridge, England: Cambridge University Press. http://doi.org/dr7gwb

Grimm, K. J., \& Widaman, K. F. (2010). Residual structures in latent growth curve modeling. Structural Equation Modeling: A Multidisciplinary Journal, 17(3), 424-442. http://doi.org/bcwtg9

Harrison, R. (2016). Andrew Mehrtens-the newest te reo Māoricrusader. Māori Television. Retrieved from http://www.Māoritelevision.com/news/ sport/andrew-mehrtens-newest-te-reo-Māoricrusader

Hornberger, N. H. (1998). Language policy, language education, language rights: Indigenous, immigrant, and international perspectives. Language in Society, 27(4), 439-458. http://doi.org/c7b9

Ka'ai-Mahuta, R. (2011). The impact of colonisation on te reo Māori: A critical review of the state education system. Te Kaharoa, 4(1), 195-225. http://doi.org/c7cb

King, J. (2001). Te kōhanga reo: Māori language revitalization. In L. Hinton \& K. Hale (Eds.), The green book of language revitalization in practice (pp. 119-131). San Diego, CA: Academic Press. http://doi.org/c7cc

Kukutai, T., \& Rarere, M. (2015). Te ao huriburi: Iwi identification in the Census (NIDEA Brief, No. 5). Hamilton, New Zealand: National Institute of Demographic and Economic Analysis, University of Waikato. Retrieved from http://hdl.handle. net/10289/9764

Milne, B. J., Byun, U., \& Lee, A. (2013). New Zealand Socio-economic Index 2006. Wellington, New Zealand: Statistics New Zealand.
Nairn, R., Moewaka Barnes, A., Borell, B., Rankine, J., Gregory, A., \& McCreanor, T. (2012). "Māori news is bad news": That's certainly so on television. MAI Journal, 1(1), 38-49.

New Zealand Qualifications Authority. (2016, May). The New Zealand Qualifications Framework. Retrieved from https://www.nzqa.govt.nz/assets/ Studying-in-NZ/New-Zealand-QualificationFramework/requirements-nzqf.pdf

Nicholson, R., \& Garland, R. (1991). New Zealanders' attitudes to the revitalisation of the Māori language. Journal of Multilingual \& Multicultural Development, 12(5), 393-410. http://doi.org/ bmzbjt

Pettigrew, T. F., \& Tropp, L. R. (2008). How does intergroup contact reduce prejudice? Metaanalytic tests of three mediators. European Journal of Social Psychology, 38(6), 922-934. http://doi.org/fmsx4r

Pool, I. (2013). Te iwi Māori: Population past, present and projected. Auckland, New Zealand: Auckland University Press.

Radio New Zealand. (2015). Te reo stance wins plaudits. RNZ. Retrieved from http://www. radionz.co.nz/news/national/266391/te-reostance-wins-plaudits

Reedy, T. (2000). Te reo Māori: The past 20 years and looking forward. Oceanic Linguistics, 39(1), 157-168. http://doi.org/ctgsqs

Rubin, D. B. (1987). The calculation of posterior distributions by data augmentation: Comment: A noniterative sampling/importance resampling alternative to the data augmentation algorithm for creating a few imputations when fractions of missing information are modest: The SIR algorithm. Journal of the American Statistical Association, 82(398), 543-546. http://doi.org/ b7w8jp

Santiago, P., Tremblay, K., Basri, E., \& Arnal, E. (2008). Tertiary education for the knowledge society. Paris, France: Organisation for Economic Co-operation and Development. http://doi.org/ $\mathrm{d} 5 \mathrm{pv} 8 \mathrm{v}$

Satherley, N., Milojev, P., Greaves, L. M., Huang, Y., Osborne, D., Bulbulia, J., \& Sibley, C. G. (2015). Demographic and psychological predictors of panel attrition: Evidence from the New Zealand Attitudes and Values Study. PLoS ONE, 10(3), 1-22. http://doi.org/c6nx

Sengupta, N. K., Barlow, F. K., \& Sibley, C. G. (2012). Intergroup contact and post-colonial ideology: Outgroup contact ameliorates symbolic exclusion but not historical negation. International 
Journal of Intercultural Relations, 36(4), 506-517. http://doi.org/fx37t6

Sibley, C. G. (2019). Sampling procedure and sample details for the New Zealand Attitudes and Values Study. Retrieved from https://cdn.auckland.ac. nz/assets/psych/about/our-research/nzavs/ NZAVSTechnicalDocuments/NZAVSTechnical-Documents-e01-Sampling-Procedureand-Sample-Details.pdf

Social and Population Statistics Group of Statistics New Zealand. (2002). 2001 Survey on the health of the Māori language. Retrieved from http://archive.stats.govt.nz/browse_for_stats/ people_and_communities/maori/2001-surveyon-the-health-of-the-maori-language.aspx

Statistics New Zealand. (2013a). Census QuickStats about culture and identity. Retrieved from http://archive.stats.govt.nz/ /media/Statistics/ Census $/ 2013 \% 20$ Census/profile-and-summary-reports/quickstats-culture-identity/ quickstats-culture-identity.pdf

Statistics New Zealand. (2013b). Subnational population estimates (RC, constituency), by age and sex, at 30 June 2013-15 (2015 boundaries). Retrieved from http://nzdotstat.stats.govt.nz/wbos/Index. aspx?DataSetCode=TABLECODE7508\#
Te Puni Kōkiri. (2008). The health of the Mãori Language in 2006. Retrieved from http://www. tpk.govt.nz/en/a-matou-mohiotanga/language

Te Puni Kōkiri. (2010). 2009 Survey of attitudes, values and beliefs towards the Mãori language. Retrieved from http://www.tpk.govt.nz/ en/a-matou-mohiotanga/language

Tobias, M., Bhattacharya, A., \& White, P. (2008). Cross classification of the New Zealand population by ethnicity and deprivation: Trends from 1996 to 2006. Australian and New Zealand Journal of Public Health, 32(5), 431-436. http:// doi.org/dqqzvx

Tuckey, K. (2016). Te reo enriching for youngsters, and achievable for teachers. Stuff. Retrieved from http://www.stuff.co.nz

Waitangi Tribunal. (1986). Report of the Waitangi Tribunal on the te reo Māori claim. Retrieved from https://forms.justice.govt.nz/search/Documents/ WT/wt_DOC_68482156/Report\%20on\%20 the $\% 20 \mathrm{Te} \% 20$ Reo $\% 20$ Maori\%20Claim $\% 20 \mathrm{~W}$.pdf

Walker, R. (1987). Nga tau tohetohe: Years of anger. Auckland, New Zealand: Penguin. 